\title{
The Effectiveness of Application of Writing Strategies in Writing Instruction
}

\author{
Chenrong Han \\ School of Foreign Languages, Yunnan Normal University, Kunming, China
}

\begin{abstract}
Research on writing strategies has been a well-established field in second language writing research and the application of writing strategies in pedagogy has been widely acknowledged to effectively improve the process and product of English composition. This article explores how English as a foreign language learner's writing strategy use within both traditional cognitive views and sociocultural perspective. While ESL composition research actively investigates writing strategies on English majors in university, less attention has been directed to non-English majors and their composing situations differ from those of English majors. This article attempts to begin to fill this gap. The findings from this study are concluded about the specific solutions that can be practiced in writing instruction and suggest future directions of writing strategy research.
\end{abstract}

Index Terms-writing strategies, sociocultural approach, cognitive strategy, College English course, EFL learners, mediated actions

\section{INTRODUCTION}

Language proficiency, L1 writing competence, use of cohesive devices, metacognitive knowledge about the writing task, writing strategies and writers' personal characteristics, all these factors has been illustrated by Angelova (1999) to affect the process and product of English as foreign language (EFL) writing. Among all above factors, writing strategies seem exceedingly significant to ESL writing since many researchers (Arndt, 1987; Victori, 1995; Zamel, 1982; Beare, 2000) assert that "it is the writing strategies that primarily separate successful from less successful writers" (Mu, 2005, p.1). To my knowledge, one of the earliest researches on ESL writing strategies is Arndt's investigation in the year of 1987. She focused on six Chinese EFL students about their activities of writing composition and analyzed their written texts produced by both their first language and foreign language. Eight categories were adopted to code Chinese students' writing strategies: planning, global planning, rehearsing, repeating, re-reading, questioning, revising and editing. The other example of writing strategies' studies is investigated by Wenden (1991). Wenden investigated eight ESL students by requiring them to compose a writing task at the computer and researched how the learners used metacognitive strategies in their writing. According to her findings, metacognitive strategies involving planning, evaluation and monitoring are mental operations that learners use to regulate their learning. The features of these two researches are to see writing as essentially a cognitive process in which "writers discover and reformulate their ideas as they attempt to approximate meaning" (Zamel, 1983, p.165) and consider that writers use a series of cognitive strategies to accomplish writing assignments.

In contrast to traditional cognitive view of writing strategies, some specialists (e.g., Engeström, 1987; Lantolf \& Appel, 1994; Lantolf, 2006) drew on sociocultural studies to "understand how mental functioning is related to cultural, institutional, and historical context" (Wertsch, 1998, p.24). The key to the sociocultural approach is Vygotsky (1978)'s view of mediation, which indicated that humans "are able to make indirect connections between incoming stimulation and their responses through various links" (Lei, 2008, p.219). Such indirect connections are seen as "mediation", which is realized via two means: tools and signs (Vygotsky, 1978). By the means of tools, people learn to control their behaviors from the outside; via the application of signs, it is possible for people to regulate their mind from the inside. Therefore, the idea of mediation by both tools and signs build a bridge between humans and society and culture.

The concept of mediation was developed into Activity Theory (Engeström, 1987, 1999) by situating individuals' behaviors in collective activities. Several L2 specialists such as Donato and McCormick (1994) have directly explored the implication of activity theory for SLA. In terms of writing research, some experts (e.g., Prior, 2001, 2006; Russell, 1995, 1997; Villamil \& de Guerrero, 1996) pay more attentions on the application of mediation analysis and Activity Theory. According to Activity Theory, Lei $(2008,2012)$ argued that writing strategies are "mediated actions which are consciously taken to facilitate writer's practices in communities" (Lei, 2008, p.220) and identified four types of writing strategies by drawing on the Activity Theory. They are artifact-mediated, rule-mediated, role-mediated and community-mediated strategies.

In the study of ESL writing history, Silva (1990) roughly divided ESL writing instruction into four stages which separately are achieved by four approaches: the controlled approach, the current-traditional rhetoric approach, the process approach and the social approach. Mu (2005) in his studies stated that four approaches in these four stages of ESL writing instruction are supported by four important theories related to ESL writing. They are Contrastive Rhetoric Theory, Cognitive Development Theory, Communication Theory and Social Constructionist Theory. The relationship 
between writing instruction approaches and theories of classification of writing strategies is displayed in Table 1 . The Contrastive Rhetoric Theory, Cognitive Developmental Theory and Social Constructionist Theory correspond with the current-traditional rhetoric approach, the process approach and the social approach of ESL writing instruction respectively. The Communication Theory is reflected in all these four approaches of ESL writing instruction.

TABLE. 1

\begin{tabular}{ll} 
& TABLE. 1 \\
\hline Writing instruction approaches & Theories of classification of writing strategies \\
\hline Current-traditional rhetoric approach & Contrastive Rhetoric Theory \\
Process approach & Cognitive Developmental Theory \\
Social approach & Social Constructionist Theory \\
Controlled approach & Communication Theory \\
Current-traditional rhetoric approach & \\
Process approach & \\
Social approach & \\
\hline
\end{tabular}

Combining classification of writing strategies of $\mathrm{Mu}$ (2005) with exploration of writing strategies within the Activity Theory framework From Lei's $(2008,2012)$ investigation, I will discuss how writing strategies make implication of pedagogy in College English Course, which is a compulsory course for freshmen and sophomore except for English majors. Strategy use, in my opinion, should not be emphasized on either traditional-cognitive strategies or sociocultural strategies. Therefore, based on comprehensive consideration from two perspectives of writing strategies, six aspects are on following discussion. Contrastive rhetoric theory, Cognitive Development theory, Communication theory and artifact-mediated, rule-mediated strategies are attributed into $\mathrm{Mu}$ and Lei's classification of writing strategies respectively. Society-mediated strategy is one of subcategories of Community-mediated strategies according to Lei (2008, 2012). Nevertheless, Mu (2006) identified social factors into a category of writing strategies: social Constructionist Theory. It is suggested that society-mediated strategies are mainly discussed. Additionally, I strongly consider that role-mediated strategies are closely related to social-mediated strategies, which will be analyzed in part of social-mediated strategies as well.

\section{RESEARCH QuESTIONS}

The purpose of this study is to explore the solutions of following problems revealed from practical instruction in College English Course with the results of writing strategy research.

- For college students, it is seldom difficult to analyze the elements of paragraph during the reading course by correctly pointing out topic sentences and support sentences and understanding where to use classification, exemplification, comparison and definition. However, while composing writings, they present their ideas just with simple sentences and disordered paragraph structure. Especially for those good EFL learners, there is an embarrassing situation that they are not able to break the barrier between what they have learnt and what they want to write. They always have a habit of expressing in easy words and sentences that makes a negative influence on facilitation of writing. Perl concludes this phenomenon as "stable composing process" (Perl, 1979, p.328) for unskilled writers but in my experience there is no exception for most skilled writers. The single difference is differently "stable" composing process.

- Improper use of the Internet. Instead of collecting useful information, obtaining brainstorming ideas, and reading some online samples writings via the Internet, many learners tend to depend on an online thesaurus completely. They are addicted to use online dictionary to resolve all problems, not realizing that the differences between L1 and L2 and they are not entitled to use any dictionaries in examinations. It is commonly realized that in College English class some novice students might come upon an embarrassing situation that he or she submits a same composition as his or her classmates. They do not know how to write in English but download from the Internet.

- Most EFL learners in College English Course view each skill of English acquisition separately and commonly believe that their reading ability is better than writing ability, which they extremely are confused how to improve it or have a very limited notion of what composing involves. Moreover, through daily observation of EFL learners in College English class, they seldom develop their writing ability by obtaining assistance from others except for the in-class instruction from teachers as a result of emotional elements such as pudency and ignorance of problems.

- Some students can easier translate an English sentence into Chinese than translate same sentence from Chinese to English. Additionally, while reading an English article, some students can understand what it means, but cannot speak it out in Chinese with the proper language transformation.

\section{DISCUSSION}

\section{A. Contrastive Rhetoric Theory}

Contrastive rhetoric theory is proposed by Kaplan (1966) in his essay 'Cultural Thought Patterns in Intercultural Communication'. Research in contrastive rhetoric indicated that textual differences written by native and non-native speakers of English were related to their respective cultural differences. Since this theory was emerged it has experienced numerous criticisms; however, even with so many criticisms for a number of years, contrastive rhetoric has 
played a very important role in ESL writing classroom (Silva, 1990). As Silva (1990) noted, the elements of paragraphs such as topic sentences, support sentences, and transitions as well as various choices for its development such as illustration, exemplification, comparison, contrast, classification and definition are involved in the theory of contrastive rhetoric.

Although it is a distinct question that most less-proficiency EFL learners have already realized, they have no ideas how to resolve it and facilitate their writings effectively. Instructors could help learners make more commitment on capturing a topic sentence that entirely and correctly summarize certain paragraph and stating supported details logically. To those who have occupied correct grammatical expectations and conventions, instructors should encourage them to use skills such as classification, exemplification, definition and contrast to facilitate writings. Additionally, interpretation of reading material and ideas refinement is the practical pedagogies based on contrastive rhetoric theory. For instance, in the textbook 'New Horizon College English' (second edition) Book 3, there is a reading text about "iron deficiency". Interpretation of problems on iron deficiency and refining suggestions to prevent iron deficiency are beneficial of composing under relevant topics such as how to keep health, women health, adult health, healthy diet, etc. From another text about solitude recorded in book---New Horizon College English (second edition) Book 4, students seems to hardly impress how an artist opts a solitary living style to obtain the inspiration. Teachers could help learners conclude the advantages and disadvantages of living alone or living with roommates and set an example to how to expand these objectives into some writing topics: "what is your ideas about dormitory life?", "what is your opinions about the Internet life-style?" which breaks an illusion for some learners that identical opinions cannot support different topics.

\section{B. Cognitive Development Theory}

Cognitive development theory, "which emerged in Europe in the eighteenth century, was concerned with nature of knowledge and with the structures and processes by which it is acquired" (Mu, 2005, p.2). Perhaps the most contribution of cognitive development theory is to raise the discussion of process that is obviously associated with Flower and Hayes's model (1981) and Bereiter and Scardamalia's model (1987). Flower and Hayes (1981) viewed English writing as a recursive process in which planning, generating, translating and editing need to work together without regular procedure as well as a single process for all writers in which skilled writers do the same as less-skilled ones. Consequently, Flower and Hayes's model (1981) revealed an obvious limitation that it was not able to account for the differences between proficient writers and novice writers. Based on think-aloud protocol analysis, experimental research and direct observation, Bereiter and Scardamalia (1987) propose two models of writing: knowledge-telling model for novice writers and knowledge-transformation model for expert ones. The former model does not involve any complex problem-solving activities while the latter model requires writers to produce a series of reflective behaviors that involve transformations of information to solve content and rhetorical problems during the period of composition.

Although limitations existed in both theories, Flower and Hayes's model and Bereiter and Scardamalia's model gave a good indication of research on ESL writing. In College English class, identical requirement of writing assignment for all students is clearly an unadvisable decision. Given the practical instruction, I all along insist on applying for different pedagogies to guide novice and expert writers to compose. The primary prospective for novice is to cultivate them to tell ideas in writing conventions that are acceptable to native English speakers. Conservative expressions, which mean structures are easily mastered, combined with less rhetoric transformation should be encouraged by doing more trainings in writings for novices. Through such goal-directed practice, novice writers could write smoothly and exactly express their ideas by avoiding some grammar errors both in routine assignments and exam task. This point can be emphasized by a negative example that novice writers usually entirely depend on online-translation device to finish composition since it is seen as an impossible mission beyond their English proficiency. In contrast, for good ESL learners, there is no virtual facilitation for their writing under the instruction of knowledge-telling theory. Therefore, instructors need to endeavor to deliver knowledge transforming process of writing through revising their writings. Instead of merely focusing on grammatical errors, improvement on writing should be paid more concentration in terms of proper use of vocabulary, complex sentence structure, connecting, etc.

\section{Communication Theory}

Kennedy (1998) indicated that it is the social and political purposes of discourse rituals that Communication theory highlights, "specifically discourse-in-use, where interpersonal communication is grounded in beliefs about individualism and independent interaction in society and investigates multiple levels of discourse (economical, social, material, institutional, and cultural)" (Mu, 2005, p.3). To realize the connection between communication theory and writing studies, discourse is obviously emphasized to reach an important position. According to communication theories, different discourses are compatible with different communicative purposes. Cooper and Odell (1977) have identified various styles of written discourses such as dramatic, personal, academic writing, business writing, technical writing, fiction and poetry. Writing strategies of discourse is no doubt to guide the effective writing for ESL learners, which is proved by the instruction of academic writing. For most College English learners, writing is just a written expression that is simply transformed from oral expression in English. It is general to see some oral expressions in learners' essays, which seems too much like a record of a speech. Students should be required to understand disciplines of academic writing and master the genres and conventions of an academic discourse community to write a real academic essay. 
With the correct direction of communicative strategies, writing becomes a process to express writers' ideas in a most effective way. This is also the definition of communicative strategies from Cohen (1998).

\section{Artifact-mediated Strategies}

Since the artifacts include tools and signs, artifact-mediated strategies are categorized as tool-mediated and sign-mediated strategies. According to the results of investigation from Lei (2012), four types of artifacts---English literacy works, the Internet, the L1 (Chinese) language and the L2 (English) language---are mainly used by EFL learners to mediate into their writing. Both the Internet-mediated and literary work-mediated strategies are classified into the tool-mediated strategies while L1 and L2 language are the most prominent subcategories of sign-mediated strategies.

With regard to the promotion of EFL learners in College English Course, I have the experience that these subcategories could function simultaneously and complementary to boost learners' English proficiency of writing. I hold a strong agreement with Lei (2012) that English literary works can be used as a major artifact to develop students' writing strategy use. However, in the class of College English course, students who are unlike English majors rarely read any English literary works other than materials in textbooks, which means instructors need to employ textbooks comprehensively to not only enhance reading ability but also importantly raise their writing competence.

Facing with vocabularies and sentence structures in readings that can be easily transferred into compositions, experienced teachers should lecture learners to use brains actively by imitating the language use in literary works with their own expressions. Moreover, instructors should enhance positive transformation both from Chinese to English and English to Chinese, avoiding Chinglish expression. Teachers should balance the exercises of translations. When students are having a habit of translating from English to Chinese, teachers should consciously guide them to do more practices oppositely---from Chinese to English---with the instruction of similarities and differences between two languages. As it is difficult to immerse in an English environment while living in a Chinese-speaking society for most college students, the more effective practices is to master the differences and similarities between L1 and L2 and further remedy Chinglish expression.

There is no any objection that the Internet is fast, convenient, up-to-date, and full of resource. However, under my observation, its disadvantages surpass its advantages constantly with the lack of cognition of the Internet's weaknesses and excessive exaggeration of its strengths. Some students make an equation with dictionary and the Internet with frequent using of online thesaurus. The neglect of usage of words is not beneficial of writing. Therefore, instructors necessarily encourage learners use non-electronic dictionary to pinpoint vague words in their minds, check the usage of some words they knew, explore new meanings of words they have learnt and analyze sample sentences to imitate in their own compositions. In fact, the Internet that is viewed as a main source of information is definitely worthy of advocating, especially in the preparation period of writing. For instance, various opinions of a topic easily scanned on the Internet could make a brainstorming for learners; relevant information of topic collected via the Internet could purposefully enrich materials for writing activities.

The artifact-mediated strategies significantly contribute to ESL learners' writing. However, its function on writing is not always constant. Misunderstanding of certain subcategories of artifact-mediated strategies could produce some negative effects on composition, which should be avoided by appropriate instruction. Instructors prefer to raise learners' consciousness of using artifacts in writing and enhance their ability to use them effectively.

\section{E. Rule-mediated Strategies}

Rules refer to "the norms and sanctions that specify and regulate the expected correct procedures and acceptable interactions among the participants" (Cole \& Engeström, 1993, p.7). According to Lei's (2012) investigation, three types of rule-mediated strategies in her participants' writing are actively employed: rhetoric-mediated, assignment vs. exam rule-mediated, and evaluation criteria-mediated strategies. In my opinion, the term of rhetoric-mediated strategy is similar to the Contrastive Rhetoric theory of Wu's (2005) research. In this section, I draw more attention to two other subcategories of rule-mediated strategies: assignment vs. exam rule-mediated and evaluation criteria-mediated strategies.

In Lei's investigation (2012), the participants are English majors who are free to express ideas in the assignment; in contrast they consciously please examiners to get a high score by pursing various vocabularies and performing their writing abilities. However, in College English class there is a different situation. Some students copy good sentences or even employ online-translation device to complete assignments with the purpose of giving teachers a good impression. When they are in a real exam, especially confronting an unfamiliar topic, due to lack of effective and accurate practices in peacetime, these learners difficultly achieve a piece of "perfect" composition like they do in daily task. Although instructors have few opportunities to supervise students to write in class, they would emphasize the correct writing methods with the combination of artifact-mediated and rule-mediated strategies and clarify that one of the goals to write is to explode mistakes and weaknesses. Additionally, instructors should as well encourage them to write articles within the duration as exam provides and without any assists from any dictionaries. Through these practices, students are no longer afraid of writing when they are in exam.

To write an assignment well, students all know that they have to follow certain evaluation criteria. I used to hear an argument from one of my students that her writing is very good because it accords with requirement of her middle 
school's English teacher. And it is another common phenomenon that tedious narrations replace summarized arguments in genre of argumentative writing, which gives me a signal that evaluation criteria of writing in college education should be instructed to learners primarily. Natural English expression, profound thoughts, clear-organized structure, clear logic and accurate diction that are definitely the characteristics of a good writing should be valued greatly in college students' mind to evaluate their composition.

\section{F. Society-mediated Strategies}

Social constructionists believe that we do not "find or discover concepts, models, and knowledge as much as we construct or make them" (Mu, 2005, p. 3). In regard of the function of society-mediated strategies to composition instruction, the importance of teaching within students' zones of proximal development (ZPD) should be highlighted. According to Vygotsky's (1978) work, Carol stated that "teachers can bridge the gap between the level of performance attained by the student in independent problem solving and the level attained in collaborative problem solving with the teacher and more knowledgeable other" (Carol, 1992, p.162), a gap that Vygotsky refers to as the ZPD. Standing on the angel of learners, Dixon-Krauss (1996) believed that learning to write within the ZPD occurs when students engage in a task that is too difficult for them to perform independently, forced them to seek support and assistance from more capable peers for their writing performance or organize peers to complete collectively.

For the above perspective, teachers can scaffold learning in various ways to teach within students' learning zones. For example, teachers can help some students who have difficulties knowing what information to include ask a series of graduated questions that push students retrieve relevant information. Moreover, teachers can organize some activities to give rise new understandings and awarenesses by using students' everyday knowledge and experiences.

In Lei's (2008) studies, all participants alerted that they would actively and consciously find assistance from competent peers, English elites, and even communication in virtual communities; whereas in Lei's (2012) research, in terms of society-mediated strategies, participants believed that the "ultimate goal of their learning to write on campus was to socialize with people in society" (Lei, 2012, p.182). With the comparison of two researches, society-mediated strategies are reflected in the process of writing composition and the goal of writing. That is to say that teachers should adopt society-mediated strategies in response to different desires from students and society-mediated strategies, as a subcategories of community-mediated strategies, is firmly compatible with role-mediated strategies.

The community comprises "multiple individuals and/or subgroups who share the same general object and who construct themselves as distinct from other communities" (Center for Activity Theory and Developmental Work Research, 2007). Role describes "the continuously negotiated distribution of tasks, powers, and responsibilities among the participants of the activity system" (Cole \& Engeström, 1993, p.7). In same or different community, each individual could play different role. Teachers who effectively involve with community-mediated and role-mediated strategies can improve writing competence for students and raise learners 'consciousness of participation. Students naturally have a habit of being a novice facing their teachers. To fulfill a same assignment, instructors probably position students in the role of experts to explain, readers to evaluate where students can practice discourse, skills, strategy and other abilities. Except for the instructors, peers play also an important role in supplementary impacts on learning writing. With the combination of community-mediated and role-mediated strategies, teachers can encourage learners to participate in various community activities such as group discussion, writing interesting groups, peer revision where learners with same level of English proficiency can socialize with other community members and get information from their peers. Role of certain individual probably is not a learners but an instructor. Students-to-student interactive dialogues are more functional instead of teacher-to-student interactive dialogue that is a traditional kind of feedback for English learning. Lastly, instructors can enrich writing contents for future careers such as CV, proposal, speech, project and discipline, agreement, enhancing their social consciousness by transforming their role from simple English language learners to language users.

\section{CONCLUSIONS AND IMPLICATIONS}

These findings lead to conclusions about the solutions of questions appearing in regular educational practice posed at the beginning of the study, and have implications of mediation of writing instruction. Lastly, the emphasis on raising to self-consciousness that EFL learner should employ various strategies and strategy adaptations, more importantly, reach interactions between across various writing strategies.

In this article, research on application of writing strategies is conducted to examine the effectiveness of instructing students in writing where the real goal is to achieve authentic and meaningful communication. As mentioned above, learners in College English Course are not like English majors, who can engage in regular exclusive writing courses and obtain systematic and professional instructions within a small-scale class. Therefore, the appropriate application of writing strategies that provides an effective teaching to EFL learners should be paid more attention. The writing strategies guided by Contrastive rhetoric theory lead to the correct and proper expressions in writing progress and interpretation of reading materials rather than isolating writing from reading skills. The cognitive development theory implies that distinct pedagogies are employed to skilled- or unskilled EFL learners while confronting students with a wide range of English proficiency. Emphasis on discourse is inevitable explaining the application of communication theory in writing studies, which has been commonly approved and widely practiced in EFL education. 
Mediation serves as a key-word in discussion of writing strategies from the sociocultural perspective. Artifact-mediated and rule-mediated writing strategies through English literacy works, the Internet, L1 \& L2 language, assignment vs. exam rule and evaluation criteria, are used to effectively complete the composition. In addition, writing should be presented as a collaborative and social activity rather than a solitary. Involving the relationship between society-mediated, role-mediated and community-mediated strategies, I draw a conclusion that instructors should create various communities to encourage learners to be different roles in order to make learners understand the importance of society-mediated strategies affecting the process and product of writing. The learners should break the traditions that writing is a private experience with few opportunities to interact.

Despite above discussed mediations in writing instruction, awareness of audience and purpose of writing is consciously mediated into EFL writing by teachers. Writers' purpose should be the communication with a certain potential reader as Zamel (1983) indicated that skilled ESL writers "understood the importance of taking into account a reader's expectations" (Zamel, 1983, p.178). It is a good means that in the course of composing writers tend to establish an audience for its composition and view the task as lively dialogic interaction with a reader to make more improvement on the writing instead of seeing the task solely just as a linguistic assignment. Instructors should encourage students to do more sophisticated understanding of themselves as authors to fulfill the requirement from their audiences in the literacy community.

Each writing strategy could not be considered being solitary. To realize the purposes of effectiveness of writing instruction, in the classroom given the different situation of learners and teaching experience, combination of various writing strategies to convey language knowledge and techniques should be served as a priority. While realizing that the meaning embedded in highly structured learning materials is not sufficient to transfer to students, some teachers began to use the concept of mediation in their class. However, instructors should clarify that not every mediation affect learner's English proficiency though they received a great deal mediations in the progress of interaction. Consequently, teachers primarily aim at assisting students distinguish which writing strategy and what kind of mediation can positively influence on their writing and enhance their ability of improving composition without the guidance of instructors.

Writing is not just as one of the language skills to be mastered, or the most prominent skills to be learned, but as an effective way for an EFL learner to accumulate vocabulary, generate sentences, experience chunks of discourses and ultimately communicate them in English language.

\section{REFERENCES}

[1] Angelova, M. (1999). An exploratory study of factors affecting the process and product of writing in English as a foreign language. Unpublished PhD dissertation, State University of New York, Buffalo.

[2] Arndt, V. (1987). Six writers in search of texts: A protocol-based study of L2 and L2 writing. ELT Journal, 41, 257-267.

[3] Beare, S. (2000). Differences in content generating and planning processes of adult L1 and L2 proficient writers. Unpublished $\mathrm{PhD}$ dissertation, University of Ottawa.

[4] Bereiter, C., \& Scardamalia, M. (1987). The psychology of written composition. Hillsdale, NJ: L. Erlbaum.

[5] Carol, S. E. (1992). Writing instruction from a sociocultural perspective: The holistic, dialogic, and social enterprise of writing. Journal of Learning Disabilities, 25(3), 153-172.

[6] Center for Activity Theory and Developmental Work Research. (2007). Cultural-Historical Activity Theory. Retrieved February 11, 2007, from http://www.edu.helsinku.fi/activity/pages/chatanddwr/chat/.

[7] Cohen, A. D. (1998). Strategies in learning and using a second language (First ed.). New York: Addison Wesley Longman Limited.

[8] Cole, M., \& Engeström, Y. (1993). A cultural-historical approach to distributed cognition. In G. Salomon (Ed.), Distributed cognitions: Psychological and educational considerations. 1-46. Cambridge: Cambridge University Press.

[9] Cooper, C. R., \& Odell, L. D. (1977). Evaluating writing: Describing, measuring, judging. Urbana, IL: National Council of Teachers of English.

[10] Dixon-Krauss, L. (1996). Vygotsky in the classroom: Mediated literacy instruction and assessment. White Plains, NY: Longman.

[11] Donato, R., \& McCormick, D. (1994). A sociocultural perspective on language learning strategies: The role of mediation. The Modern Language Journal, 78(4), 453-464.

[12] Engeström, Y. (1987). Learning by expanding: An activity theoretical approach to developmental research. Helsinki: Orienta-Konsultit Oy.

[13] Engeström, Y. (1999). Activity theory and individual and social transformation. In Y. Engeström, R. Miettinen \& R.-L. Punamäki (eds.), Perspectives on Activity Theory, 19-38. Cambridge: Cambridge University Press.

[14] Flower, L., \& Hayes, J. R. (1981). A cognitive process theory of writing. College Composition and Communication, 32, 365-387.

[15] Kaplan, R. B. (1966). Cultural thought patterns in intercultural communication. Language Learning (16), 1-20.

[16] Kennedy, M. L. (Ed.). (1998). Theorizing Composition: A Critical Sourcebook of Theory and Scholarship in Contemporary Composition Studies. Westport, USA: Greenwood press.

[17] Lantolf, J. P. (2006). Sociocultural theory and L2. Studies in Second Language Acquisition, 28, 67-109.

[18] Lantolf, J. P. \& Appel, G. (eds.). (1994). Vygotskian Approaches to Second Language Research. Norwood, NJ: Ablex.

[19] Lei, X. (2008). Exploring a sociocultural approach to writing strategy research: Mediated actions in writing activities. Journal of Second Language Writing, 17(4), 217-236.

[20] Lei, X. (2012). Understanding Good language Learners' Writing Strategy Use in the Chinese EFL Context: A sociocultural 
Perspective. Chinese Journal of Applied Linguistics, 35(2), 175-188.

[21] Mu, Congjun. (2005). A Taxonomy of ESL Writing Strategies. In Proceedings Redesigning Pedagogy: Research, Policy, Practice, May 30-Jun 1, 2005, 1-10, Singapore. (Unpublished)

[22] Perl, S. (1979). The composing processes of unskilled college writers. Research in the Teaching of English 13(4): 317-336.

[23] Prior, P. (2001). Voices in text, mind, and society: Sociohistoric accounts of discourse acquisition and use. Journal of Second Language Writing, 10, 55-81.

[24] Prior, P. (2006). A sociocultural theory of writing. In C. A. MacArthur, S. Graham, \& J/ Fitzgerald (Eds.), Handbook of writing research, 54-66. New York: The Guilford Press.

[25] Russell, D.R. (1995). Activity theory and its implications for writing instruction. In J. Petraglia (Ed.), Reconceiving writing, rethinking writing instruction, 51-77. Mahwah, NJ: Lawrence Erlbaum Associates.

[26] Russell, D. R. (1997). Rethinking genre in school and society: An activity theory analysis. Written Communication, 14(4), 504-554.

[27] Silva, T. (1990). Second Language composition instruction: developments, issues, and directions in ESL. In B. Kroll (Ed.), Second Language Writing Research: Insights for the classroom. 11-17. New York: Cambridge University Press.

[28] Victori, M. (1995). EFL writing knowledge and strategies: An interactive study. Unpublished PhD dissertation, Universitat Autonoma de Barcelona (Spain), Barcelona.

[29] Vygotsky, L. S. (1978). Mind in society: The development of higher psychological processes. Cambridge, MA: Harvard University Press.

[30] Wender, A. L. (1991). Metacognitive strategies in L2 Writing: A case for task knowledge. In J. E. Alatis (Ed.), Georgetown University Round Table on Languages and Linguistics 1991 (pp. 302-322). Washington, D. C.: Georgetown University Press.

[31] Wersch, J. V. (1998). Mind as Action. New York: Oxford University Press.

[32] Zamel, V. (1982). Writing: The process of discovering meaning. TESOL Quarterly, 16(2), 195-209.

[33] Zamel, V. (1983). The composing processes of advanced ESL students: Six case studies. TESOL Quarterly, 17, 165-187.

Chenrong Han was born in Kunming, China in 1981. She received her Master degree in Cross Cultural Communication from Sydney University, Australia in 2006.

She is currently a lecturer in the School of Foreign Languages, Yunnan Normal University, Kunming, China. Her research interests are English teaching, ESP, SLA. 